\title{
Are These The Factors Driving The Intention of Urban Communities to Use Photovoltaic Solar Technology in DKI Jakarta?
}

\author{
Muhamad Al Faruq Abdullah ${ }^{1}$, Dudi Permana ${ }^{2}$, Aditya Pratama Nandiwardhana ${ }^{3}$ \\ \{alfaruq1602@gmail.com¹, dudipermana.77@gmail.com², danang.1983@ymail.com ${ }^{3}$ \} \\ Universitas Dian Nusantara, Jakarta, Indonesia ${ }^{1}$, Universitas Mercu Buana, Jakarta, Indonesia ${ }^{2}$, \\ Beijing Institute of Technology, Beijing, China ${ }^{3}$
}

\begin{abstract}
The purpose of this research is to develop the theoretical framework concept and explore the factors that drive urban communities to use photovoltaic solar power technology in DKI Jakarta. Based on the data obtained, the utilization of photovoltaic solar power technology in Indonesia is still very low. Urban society is chosen because it becomes the biggest energy consumer. The low utilization of photovoltaic solar power generation technology in urban areas may be caused by many factors, from pre-survey results obtained some dominant factors. The literature on the concept of urban community intent to use photovoltaic solar power technology is generally limited in Indonesia. So this research adds literature in the field of solar photovoltaic solar power technology by explaining conceptually the linkages between awareness,price perception and marketing communications to encourage urban people's intentions to use photovoltaic solar power generation technology. Research has found that awareness, price perception and marketing communication have a positive and significant effect towards intention to use photovoltaic solar power generation technology.
\end{abstract}

Keywords: community, intention to use, solar power plant, photovoltaic

\section{Introduction}

The national phenomenon of the national electricity crisis is occurring in Indonesia, National Energy production grew by $6.4 \%$ over the period 2015/2016 and grew by $6.3 \%$ during 1990/2016 period (Global energy statistical yearbook, 2017) Whilst the national energy demand forecast will grow by 185\% year 2025 (Outlook Energy Indonesia, 2016: 39). The total capacity of power plants in Indonesia is $55.5 \mathrm{GWp}$ consisting of fossil-fueled power plants and power plants based on Renewable Energy [1]. However, fossil fuel power plants still dominate with a capacity of $48.7 \mathrm{GWp}$ or $87.8 \%$ of the total capacity of national power plants (Electricity Statistics, 2015). Another problem is the utilization of power plants based on Renewable Energy (EBT) in Indonesia is still very low. The proportion of various EBTs is 6.7 GWp or $12.2 \%$ of the total capacity of the national power plant [2]. Special Solar Power Plant (PLTS) that is equal to $0.12 \%$ of the total capacity of the National power plant. Following the issue of electricity energy crisis, the Government issued Government Regulation (PERMEN) no. 79 of 2014 on National Energy Policy (KEN) to respond to the national energy crisis and improve the mix of New Renewable Energy sources [3]. In the National Energy Policy (KEN), the Government is committed to increase the ratio of the use 
of New and Renewable Energy (EBT) sources to $25 \%$ and lower the ratio of conventional Energy use. It triggers the research and development of new and renewable energy sources such as Mini Hydro Power Plant (PLTM), Micro hydro (PLTMh), Wind (PLTB), Sea Flow (PLTAL), Geothermal (PLTP), Waste (PLTM) PLTSa) and Surya (PLTS).

The President also issued Presidential Decree No. 4 of 2016 on the Acceleration of Electricity Infrastructure Development which explains that in order to increase the fulfillment of people's electricity demand in a fair and equitable manner and to encourage economic growth, it is necessary to accelerate the development of electricity infrastructure including the development a 35,000 MW plant and a 46,000 km transmission network prioritizing the use of renewable and renewable energy in order to support efforts to reduce greenhouse gas emissions. Therefore, the government will issue Renewable Energy Renewable Energy Roadmap for the Energy Resilience as stated in RPJMN 2015-2019 (National Medium Term Development Plan) on Renewable Energy Development prioritized for isolated areas, Utilization of environmentally friendly and renewable energy source as part of City Development strategy Climate and Disaster Resilient Green, Enhanced Innovation and Technology Capacity in EBT, Target for Increasing New and Renewable Energy Mixes, and Incentives and Funding Schemes to Encourage EBT Investments. Based on the New Renewable Energy Potential Map released by the Ministry of EMR stated that the potential of New Renewable Energy (EBT) in Indonesia reaches more than $441 \mathrm{GWp}$. Indonesia located on the equator has many advantages, one of which is solar energy available throughout the year. The potential of solar irradiance in Indonesia when converted into energy quantity, it will be equivalent to $4.80 \mathrm{kWh} / \mathrm{m} 2$ / day. The potential of land in Indonesia if converted into a capacity scale will be equivalent to $560.000 \mathrm{MWp}$ (Mega Watt Peak), but until now the potential capacity is utilized only about 70MWp only. To achieve the government's target, the support to utilize the potential of solar energy owned by Indonesia needs to be improved by the development of PLTS which is spread or centralized (communal). By doing the construction of the PLTS, it is necessary to pay attention to the land use for the construction of PLTS[4].

The development of this PLTS requires a large enough land, also requires a considerable investment for PLTS which is communal. Therefore, in urban areas, the development of PLTS can be carried out scattered by utilizing the roof of the house or rooftop that will be connected directly to the grid electricity network [5]. The PLTS system is an easy-to-use and minimal maintenance option for EBT power sources. The price of each component of the PLTS system decreases due to the increasing system efficiency [6]. However, at this time the initial investment is still considered quite large when compared with its limited energy production capacity only in the morning until late afternoon. Currently, the total investment of PLTS system is around USD $1.5 / \mathrm{Wp}$, while the energy produced daily only revolves around 4kWh / $\mathrm{kWp} /$ day. If the value in terms of investment, it took about 8 years to reach the point of ROI (Return of investment). But the above ROI prediction is still very rough because based on the assumption that PLN electricity prices are not increased[7].

Although not a new technology, PLTS system is still rarely known function and its benefits by urban communities. In line with the government program prioritizing the development of EBT power sources for isolated areas, isolated communities are more familiar with the functions and benefits of this technology as it becomes their primary source of electrical energy due to the absence of PLN's electricity grid. As for urban communities that are already familiar with PLN electricity, the EBT power plant is still considered an alternative source of energy [8]. By conducting a preliminary open question survey on its special urban community of Jakarta citizens, it appears that the community's knowledge of 
EBT's special PLT power plant technology is good enough, but as there is still some doubt to find out more and use its special EBT generating technology PLTS [9].

From the pre-survey results obtained that the issue of Awareness, Marketing Communication and Price Perception is a dominant factor that affects the urban community's special intentions of citizens of DKI Jakarta to use PLTS technology. So it is felt this phenomenon needs to be in further detail.Awareness has a positive and significant impact on Intention to Use and also showed a positive and significant influence between Awareness to Intention to Use[10]. in his research suggests that Awareness proved to positively influence as a mediation of Perceived quality and Satisfation against Behavioral Intention to Use. Revealed that Price has a positive and significant effect on Intention, this is also proved in research conducted by [11], in his research suggests that the perception of the usefulness of a good is influenced by perception of the price of the goods. And the perception of the usefulness of a good has a positive and significant effect on Intention. While Aman, [12]stated its importance Marketing Communication to Environemntal knowledge, and the results of his research showed a positive and significant influence on Green purchase intention. [13]States that Marketing Communication has a positive and significant impact on Intention.

Based on these findings, it can be identified as follows: National Electricity crisis is happening in Indonesia, National Energy Balance should be positive to happen Energy Resilience, Indonesia's power plant is dominated by fossil fuel-generated power plants, lack of awareness of citizens Indonesia specifically the urban community of new renewable energy technology (EBT), Utilization of EBT in Indonesia is still very low especially its Solar Power Generation (PLTS), lack of knowledge of urban society will function and benefit of EBT technology specially its PLTS, initial investment cost of PLTS which is still high when compared with the amount of energy that can be in production, It is necessary to communicate about PLTS technology to the urban community who still unaware to this technology.

\section{Literature Review}

\subsection{Intention to use}

Intention to use a technology is part of the technology acceptance model or TAM (Technology Acceptance Model), a theory that models how users can receive and use technology. This model shows that when users are presented with new technology, a number of factors will influence their decision about how and when they will use it (Davis 1989). TAM is one of the most influential extensions of Theory of reasoned action (TRA) presented by [1] Ajzen and Fishbein (1980). Davis's technological acceptance model is the most widely used model of user acceptance and use of technology [14] .TAM itself was developed by Fred Davis and Richard Bagozzi. TAM replaces many of the actions of TRA with two steps of technology acceptance - ease of use, and usability. TRA and TAM both have strong behavioral elements, assuming that when a person forms an intention to act, they will be free to act without restriction. In the real world there will be many obstacles, such as limited freedom to act [15].

\subsection{Awareness}

Asserts that Awareness is a component of knowledge. If consumers have knowledge about a particular product, either this knowledge is acquired actively or passively, its meaning Awareness them to the product is high [4]. Awareness or awareness describes the ability of a 
potential buyer to recognize, recall a product as part of a particular product category. Awareness is the ability of a prospective buyer to recognize or recall that a brand is part of a particular product category [10].

\subsection{Price Perception}

Price perception is the consumer's assessment and associated emotional form of whether the price offered by the seller and the price compared to the other is logical, acceptable or justifiable. Xia in Lee and Lawson (2011) argues that price perceptions are consumer ratings and associated emotional forms of whether the price offered by the seller and the price compared to the other party is logical, acceptable or justified. States that price perception is a psychological factor of many aspects that have an important influence in consumer reactions to prices[16]. Therefore, price perception is the reason why someone makes a decision to buy. Gourville and Moon instate that consumer price perceptions are influenced by prices offered by other stores with the same goods[17].

\subsection{Marketing Communication}

Marketing Communications is an activity that seeks to disseminate information, influence and persuade or remind the target of the company and its products to be willing to accept, buy loyal to the products offered by the company concerned. Marketing Communications is defined as activities and communication strategies addressed to target audiences. The purpose of public communication is to provide information to the target audiences and to raise awareness and influence the attitudes or behaviors of target audiences In addition, Communication can create more positive consumer attitudes, which will affect the willingness of consumers to buy products[6]

\section{Research Methods}

The source of research data is the subject from which data can be obtained. In this study, the authors use one source of data that is primary data source, where the data directly collected by researchers from the first source. The primary data source in this research is the special urban residents of jakarta citizens. The data used in this study is quantitative data that is the type of data that can be measured or calculated directly, in the form of information or explanations expressed by numbers or numbers. Data collection techniques used in this study by using library (library research) and field research (field research). Library research is done to obtain data about the theory that support the research. meanwhile, field research was conducted to determine the conditions that occur in the field more clearly and compare with the theory that has been obtained, by doing direct observation on the object of research and survey using questionnaire. The type of data in this study using component or variance based structural equation modeling where in data processing using partial least square (smart-pls) version 3.0 program. pls (partial least square) is an alternative model of covariance based sem. pls is intended for causal-predictive analysis in situations of high complexity and low theoretical support. While the sample will be in the care of the decision makers of each sector with a total sample of 135 respondents in Jakarta Indonesia. 


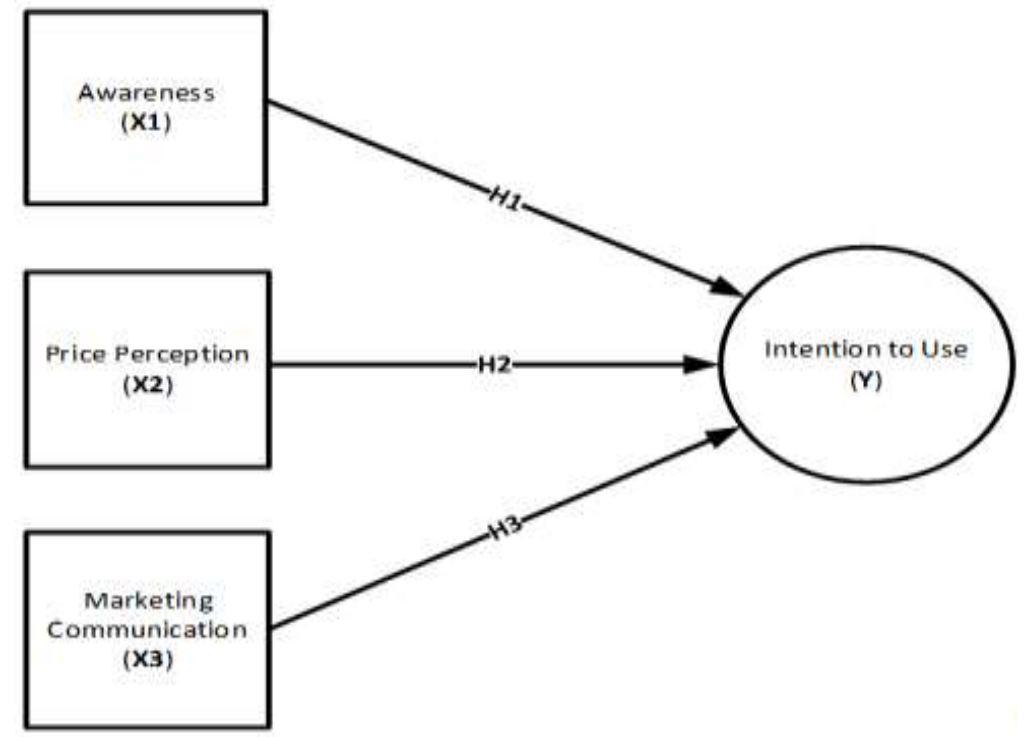

Fig. 1. Research model

Based on the findings and empirical evidence, it can be concluded the hypothesis as follows: H1: Awareness has a positive and significant impact on Intention to use.

H2: Marketing communication has a positive and significant impact on Intention to use.

H3: Price perception has a positive and significant effect on Intention to use.

\section{Result and Discussion}

\section{Profile Of The Respondents}

A total of 145 responses were received at the end of the data collection process. The profiles of respondents can be analyzed according to age, occupation, spending, and domicile. from 145 respondents, $18.7 \%$ is under 25 years old, $53.8 \%$ is aged between $25-35$ years old, and $27.6 \%$ is above 35 years old. most of the respondents most of respondents are workers with dominance of $64.1 \%$, while the rest of $24.8 \%$ is professional and business owner, $6.9 \%$ is students, and $4.2 \%$ is undefined activity. Individual spending are spread across, under 3 million per month by $22.1 \%$, in range of 3-5 million rupiah per month by $25.5 \%$, and above 5 million per month by $52.4 \%$. lastly, $68.3 \%$ of respondents are living in jakarta, while the rest $31.7 \%$ is living in sub-urban or outside of Jakarta.

\section{Results}

\section{Measurement Model}

a) Convergent Validity

The convergent validity which is the degree to which multiple items that are used to measure the same concept agree, was tested. The factor loadings, composite reliability and average variance extracted were indicators used to assess the convergent validity. 
The loading for all items exceeded the recommended value o.6 (chin et al. 1997). the composite reliability (cr) values (see table 1), which depict the degree to which the construct indicators indicate the latent construct, ranged from 0.904 to 0.924 , which exceeded the recommended value of 0.7 . The average variance extracted (ave), which reflects overall amount of variance in the indicators accounted by the latent construct, were in the range of 0.577 to 0.710 , which exceeded the recommended value of 0.5 .table 2 depicts the results of convergent validity.

\section{b) Discriminant Validity}

Discriminant validity is the extent to which the measures do not reflect other variables and it is indicated by low correlations between the measure of interest and the measures of other constructs [10].

Table 1 Factor Loadings And Reliability

\begin{tabular}{|c|c|c|c|c|}
\hline Items & Loadings $^{\text {A }}$ & $\mathbf{C R}$ & AVE & $\begin{array}{c}\text { Cronbach's } \\
\text { Alpha }\end{array}$ \\
\hline AWR01 & 0.841 & \multirow{4}{*}{0.904} & \multirow{4}{*}{0.701} & \multirow{4}{*}{0.858} \\
\hline AWR02 & 0.861 & & & \\
\hline AWR03 & 0.798 & & & \\
\hline AWR04 & 0.848 & & & \\
\hline IU01 & 0.683 & \multirow{8}{*}{0.917} & \multirow{8}{*}{0.582} & \multirow{8}{*}{0.899} \\
\hline IU02 & 0.735 & & & \\
\hline IU03 & 0.745 & & & \\
\hline IU04 & 0.782 & & & \\
\hline IU05 & 0.703 & & & \\
\hline IU06 & 0.777 & & & \\
\hline IU07 & 0.839 & & & \\
\hline IU08 & 0.826 & & & \\
\hline MC01 & 0.737 & \multirow{9}{*}{0.924} & \multirow{9}{*}{0.577} & \multirow{9}{*}{0.908} \\
\hline MC02 & 0.771 & & & \\
\hline $\mathrm{MC03}$ & 0.798 & & & \\
\hline MC04 & 0.829 & & & \\
\hline MC05 & 0.743 & & & \\
\hline MC06 & 0.809 & & & \\
\hline MC08 & 0.687 & & & \\
\hline MC10 & 0.738 & & & \\
\hline MC11 & 0.709 & & & \\
\hline PP01 & 0.803 & \multirow{2}{*}{0.907} & \multirow{2}{*}{0.710} & \multirow{2}{*}{0.863} \\
\hline PP02 & 0.847 & & & \\
\hline
\end{tabular}


CR Composite Reliability, AVE Average Variance Extracted

${ }^{\text {A }}$ Standardized Loading

Table 2 Discriminant Validity Of Construct Fornell-Lacker Criterion

\begin{tabular}{lcccc}
\hline & Awareness & $\begin{array}{c}\text { Intention To } \\
\text { Use }\end{array}$ & $\begin{array}{c}\text { Price } \\
\text { Perception }\end{array}$ & $\begin{array}{c}\text { Marketing } \\
\text { Communication }\end{array}$ \\
\hline $\begin{array}{l}\text { Awareness } \\
\text { Intention To }\end{array}$ & $\mathbf{0 . 8 3 7}$ & & & \\
$\begin{array}{l}\text { Use } \\
\begin{array}{l}\text { Price } \\
\text { Perception }\end{array}\end{array}$ & 0.684 & $\mathbf{0 . 7 6 3}$ & & \\
$\begin{array}{l}\text { Marketing } \\
\text { Communication }\end{array}$ & 0.594 & 0.619 & $\mathbf{0 . 8 4 3}$ & \\
\hline
\end{tabular}

Note: Diagonal Elements Are The Square Root Of The AVE Of The Reflective Scales While The Off Diagonals Are The Squared Correlations Between Constructs

Discriminant validity can be examined by comparing the squared correlations between the constructs and the variance extracted for construct. as shown in table 2, the squared correlations for each construct were less than the square root of the average variance extracted by the indicators measuring that construct, indicating adequate discriminant validity. Thus, the measurement model demonstrated adequate convergent and discriminant validity.

This test is a test of a structural model by looking at the value of the R-square which is the result of the goodness of fit model test.

Table 3 R-Square

\begin{tabular}{cc}
\hline Variable & R Square \\
\hline Intention to Use & 0.558 \\
\hline
\end{tabular}

Source: Researcher (2020)

The structural model indicates that the model on the Intention to Use variable can be said to be moderate, because it has a value below 0.67 and above 0.33 , namely 0.558 . The influence model of the independent latent variables (Awareness, Price Perception, and Marketing Communication) on Intention to Use provides an R-Square value of 0.558 which can be interpreted that the construct variability of Awareness, Price Perception and Marketing Communication is $55.8 \%$; while the remaining $44.2 \%$ can be explained by other variables outside those studied. 


\section{Structural Model}

Table 4 show the results of the structural model from the output of pls. awareness, price perception and marketing communication were positively related to intention to use, explaining $55.8 \%$ of the variance, thus supporting $\mathrm{h} 1, \mathrm{~h} 2$, and $\mathrm{h} 3$ of this study.

Table 4 Summary Of The Structural Model

\section{Path \\ Hypothesis \\ T Statistics \\ Results}

\begin{tabular}{llll}
\hline Awareness ->Intention To Use & H1 & 5.023 & Support \\
Price Perception ->Intention To Use & H2 & 2.463 & Support \\
$\begin{array}{l}\text { Public Marketing Communication - } \\
\text { >Intention To Use }\end{array}$ & H3 & 1.989 & Support \\
\hline
\end{tabular}

Based on the hypothesis testing in this study, it shows that Awareness has a positive and significant effect on Intention to Use. The results of this study found that Awareness had a positive and significant effect on Intention to Use. This result is obtained because someone's intention to use (Intention to Use) a product will arise if that person has awareness (Awareness) of his or her needs. Awareness of this need has led to initiatives to find solutions, leading to the intention to use (Intention to Use) Solar Power Generation Technology (PLTS).

Based on the hypothesis testing in this study, it shows the results that Price Perception has a positive and significant effect on Intention to Use. The result of this research is the perception of the usefulness of an item is influenced by the perception of the price (Price Perception) of the item. And the perceived usefulness of an item has a positive and significant effect on Intention to Use. However, it is not only the price factor that is the main factor, other factors such as experience of product quality, ease of use of the product, and convenience of using the product can lead to the intention of using Solar Power Plant Technology (PLTS).

Based on the hypothesis testing in this study, it shows the results that Marketing Communication has a positive and significant effect on Intention to Use. The results of this study indicate a positive and significant effect on Green purchase intention. Marketing Communication is an important factor affecting Intention to Use. Through advertisements, marketing promotions, and outreach, prospective users of Solar Power Plant Technology (PLTS) will be interested and impressed, which will lead to an intention to use the technology. In other words, attention given to potential users when viewing advertisements, marketing promotions, and socialization creates interest where the expectations or needs of the potential users are achieved. Thus the desire of potential users also arises, which leads to Action, namely using Solar Power Generation Technology (PLTS).

\section{Conclusion}

Based on the results of the analysis and discussion, the following conclusions can be concluded:

1. Awareness has a positive and significant effect on the Intention to Use of urban communities in Solar Power Generation Technology (PLTS). This means that if a 
potential user is aware (Aware) of their needs and is able to recognize a product that can be a solution to their needs, then this awareness will be a strong impetus that generates the intention to use the product.

2. Price Perception has a positive and significant effect on the Intention to Use of urban communities in Solar Power Generation Technology (PLTS). This means that prospective users will consider the price of the product against what benefits (Benefit) or value (Value) will be received by them when using the product. If the benefits or value offered by a product when compared to the price offered are commensurate with or above the expectations of potential users, then this will be a strong impetus that generates the intention to use the product.

3. Marketing Communication has a positive and significant effect on the Intention to Use of urban communities in Solar Power Generation Technology (PLTS). This means that prospective users have the intention to use these products because they are influenced by marketing communications, such as promotions, advertisements and socialization so that marketing communication becomes one of the factors that encourages the awakening of the intention to use these products.

With the value of R-Square $=0.558$ shows that the ability of the independent variables (Awareness, Price Perception, and Marketing Communication) in explaining the variance of the dependent variable (Intention to Use) is $55.8 \%$. Meanwhile, the remaining $44.2 \%$ is explained by other factors outside the model.

This study aims to develop the theoretical framework concept and explore the factors that drive urban communities to use photovoltaic solar power technology in dki jakarta. Research is limited only in urban areas because urban society is the largest consumer of electrical energy in indonesia. Three factors to be studied namely awareness, price perception and marketingcommunication obtained from the results of a preliminary survey in an open question to a hundred people online respondents. The answers are varied and the majority of respondents' answers are in all three factors. The limitation of this research is that there is no such a theoretical framework that can be used as a reference, so it is necessary to develop the concept of theoretical framework based on the results of pre-survey obtained. in the hope that it can be used by his next research. The data analysis technique used is variance based structural equation modeling with partial least square, because pls can be used to analyze new theoretical framework concept developed.In designing this study, several methodological limitations were considered to conduct effective study. whereas the study design was tailored to address research objectives and focused on the critical elements of this study, this study is still not doing without its limitations. One of the limitations is this research only reach those who care about new renewable energy technology. Future study in this area would benefit by strategic clarity and successful implementation of strategy to market the solar photovoltaic technology to urban community.

\section{References}

[1] X. Zha, H. Yang, Y. Yan, K. Liu, and C. Huang, "Exploring the effect of social media information quality, source credibility and reputation on informational fit-to-task: Moderating role of focused immersion," Comput. Human Behav., vol. 79, pp. 227-237, 2018.

[2] A. Ben Youssef, S. Boubaker, B. Dedaj, and M. Carabregu-Vokshi, "Digitalization of the economy and entrepreneurship intention," Technol. Forecast. Soc. Change, no. March, p. $120043,2020$. 
[3] J. Yaghoubi, M. Yazdanpanah, and N. Komendantova, "Iranian agriculture advisors' perception and intention toward biofuel: Green way toward energy security, rural development and climate change mitigation," Renew. Energy, vol. 130, pp. 452-459, 2019.

[4] V. Henriksson, C. van Houten, and M. Spib, "To Master Disaster: How SME managers can thrive and benefit from economic crises," 2016.

[5] A. Al Mamun, M. R. Mohamad, M. R. Bin Yaacob, and M. Mohiuddin, "Intention and behavior towards green consumption among low-income households," J. Environ. Manage, vol. 227, no. June, pp. 73-86, 2018.

[6] M. Mahmud, D. Soetanto, and S. Jack, "Environmental management and product innovation: The moderating role of the dynamic capability of small manufacturing firms," J. Clean. Prod., vol. 264, p. 121633, 2020.

[7] M. O'Dwyer and A. Gilmore, "Value and alliance capability and the formation of strategic alliances in SMEs: The impact of customer orientation and resource optimisation," Journal of Business Research, vol. 87. pp. 58-68, 2018.

[8] N. Kim, S. Shin, and S. Min, "Strategic marketing capability: Mobilizing technological resources for new product advantage," J. Bus. Res., vol. 69, no. 12, pp. 5644-5652, 2016.

[9] T. Ramayah, J. W. C. Lee, and O. Mohamad, "Green product purchase intention: Some insights from a developing country," Resour. Conserv. Recycl., vol. 54, no. 12, pp. 1419-1427, 2010.

[10] M. S. Han, Y. Biying, D. Cudjoe, and Q. Yuan, "Investigating willingness-to-pay to support solar energy research and development in Myanmar," Energy Policy, vol. 146, no. July, p. $111820,2020$.

[11] C. L. Hsu, C. Y. Chang, and C. Yansritakul, "Exploring purchase intention of green skincare products using the theory of planned behavior: Testing the moderating effects of country of origin and price sensitivity," J. Retail. Consum. Serv., vol. 34, no. August 2016, pp. 145-152, 2017.

[12] J. Wang, J. Bao, C. Wang, and L. Wu, "The impact of different emotional appeals on the purchase intention for green products: The moderating effects of green involvement and Confucian cultures," Sustain. Cities Soc., vol. 34, no. May, pp. 32-42, 2017.

[13] R. Li and A. Suh, "Factors Influencing Information credibility on Social Media Platforms: Evidence from Facebook Pages," Procedia Comput. Sci., vol. 72, pp. 314-328, 2015.

[14] R. Yadav and G. S. Pathak, "Young consumers' intention towards buying green products in a developing nation: Extending the theory of planned behavior," J. Clean. Prod., vol. 135, pp. 732-739, 2016.

[15] I. Weissbrod and N. M. P. Bocken, "Developing sustainable business experimentation capability - A case study,” J. Clean. Prod., vol. 142, pp. 2663-2676, 2017.

[16] J. Cenamor, V. Parida, and J. Wincent, "How entrepreneurial SMEs compete through digital platforms: The roles of digital platform capability, network capability and ambidexterity," $J$. Bus. Res., vol. 100, no. December 2018, pp. 196-206, 2019.

[17] H. Zhang, S. Gupta, W. Sun, and Y. Zou, "How social-media-enabled co-creation between customers and the firm drives business value? The perspective of organizational learning and social Capital," Inf. Manag., vol. 57, no. 3, p. 103200, 2020. 